\title{
Patient Violence in Psychiatric Residency: A Nationwide Survey
}

Tricia L. Park Ph.D.

University of Florida, Gainesville, FL

Thomas L. Schwartz M.D.

SUNY Upstate Medical University, Syracuse, NY

Follow this and additional works at: https://jdc.jefferson.edu/jeffjpsychiatry

Part of the Psychiatry Commons

Let us know how access to this document benefits you

\section{Recommended Citation}

Park, Tricia L. Ph.D. and Schwartz, Thomas L. M.D. (2001) "Patient Violence in Psychiatric Residency: A Nationwide Survey," Jefferson Journal of Psychiatry. Vol. 16 : Iss. 1 , Article 2.

DOI: https://doi.org/10.29046/JJP.016.1.001

Available at: https://jdc.jefferson.edu/jeffjpsychiatry/vol16/iss1/2

This Article is brought to you for free and open access by the Jefferson Digital Commons. The Jefferson Digital Commons is a service of Thomas Jefferson University's Center for Teaching and Learning (CTL). The Commons is a showcase for Jefferson books and journals, peer-reviewed scholarly publications, unique historical collections from the University archives, and teaching tools. The Jefferson Digital Commons allows researchers and interested readers anywhere in the world to learn about and keep up to date with Jefferson scholarship. This article has been accepted for inclusion in Jefferson Journal of Psychiatry by an authorized administrator of the Jefferson Digital Commons. For more information, please contact: JeffersonDigitalCommons@jefferson.edu. 


\title{
Patient Violence in Psychiatric Residency: A Nationwide Survey
}

\author{
Tricia L. Park, Ph.D. and Thomas L. Schwartz, M.D.
}

\begin{abstract}
Twenty percent of current psychiatric residents $(N=517)$ responded to a nationwide survey about patient violence. Thirty six percent of responders reported 630 assaults, with $74 \%$ of residents receiving 1,853 threats. While age and training level were correlated to each other $(r=.35, p<$ .001), no correlations were found between gender, age, height, weight, number of hours of violence management training and the occurrence of assault and threat. A smaller proportion of first year residents reported assaults and threats, and more males (79\%) had been threatened (females = 69\%). Sources of study bias are identified and future research directions are outlined.

(Suggested Keywords, Index Medicus MeSH: Assault, Threat, Psychiatric Residency)

A growing body of research suggests that psychiatric residents are at significant risk for experiencing patient violence during their training $(1,2,3)$. Fink, Shoer, and Burin (1991) reported that $41 \%$ had been assaulted and $48 \%$ had been threatened of 333 psychiatric residents surveyed in Pennsylvania (4). More recently, Black et al. (1994) found that a significant proportion (56\%) of residents in an Eastern psychiatry program had been assaulted, with nearly all residents receiving verbal threats (5).

While research to date consistently documents a high rate of violence against psychiatric residents, findings regarding the relationship between gender and chance of assault have been mixed. Four studies suggest that females are more apt to be assaulted $(1,2,3,6)$. However, gender differences in rate of assault were not found by Fink et al. (1991). While reasons for inconsistent findings are unclear, an important factor in appraising the relationship between gender and assault is resident size (height and weight). Only one study has assessed the correlation between height and weight and assault, and no significant relationship was found (2). However, the small sample size $(n=31)$ raises questions about the reliability of the finding.

The relationship between resident age, training level, and patient violence is also indefinite. While younger psychiatrists have been found to be at greater risk for assault, only one survey of psychiatric residents has reported a relationship between age and assault rate $(1,7,8)$. Yet, the relationship was not statistically significant. In

University of Florida, Gainesville, Florida 32608

Corresponding Author: Thomas L. Schwartz, M.D., SUNY Upstate Medical University, Psychiatry Department, 750 East Adams Street, Syracuse, New York 13210 (Thomas Schwartz@yahoo.com).
\end{abstract}


other studies, age and number of attacks have not been correlated $(2,4)$. Research by Madden, Lion, and Penna (1976) suggests that level of experience (year in training) may be associated with assault. Thus, for psychiatric residents, training year and hours of violence management training may be salient in understanding the relationship between age and assault.

Collectively, research to date suggests that psychiatric residents are at significant risk for experiencing patient violence during residency training. However, because there have been only a handful of studies conducted, and most have had small sample sizes of limited geographical scope, additional research is clearly warranted to confirm, clarify, and extend previous findings, particularly in terms of the importance of resident characteristics for patient violence.

The present study aimed to quantify and qualify assaults and threats made against psychiatric residents using a nationwide sample. In addition, this study aimed to clarify the relationship between gender, height, weight, age, training level, and number of hours of violence management training and patient violence.

Based upon previous findings, it was expected that: (1) the assault rate would be between 40 and $50 \%$; (2) the threat rate would be greater than the assault rate; (3) $<10 \%$ would report serious assaults; (4) $<30 \%$ would report multiple assaults; and (5) females and residents reporting fewer hours of training would report receiving more assaults. As residents' size was expected to elicit different patient reactions, significant relationships between height, weight, assault, and threat were not predicted.

\section{METHOD}

Subjects/Procedures

A survey developed by the authors at SUNY Health Science Center at Syracuse, New York was mailed to a sample of current residents enrolled in American Psychiatric Association (APA) accredited psychiatry training programs in the United States. The surveys were mailed between 1-97 and 4-97, and due to financial constraints, only $50 \%$ of residents $(n=2,553)$ were surveyed. Program sites were randomly surveyed. Surveys were mailed directly to residency directors with an enclosed letter requesting random survey distribution to half of currently enrolled residents.

All subjects received a survey packet including a brief cover letter describing the nature and purpose of the study, a survey, and a pre-addressed return envelope. Initially, stamps were not provided on return envelopes. However, due to the meager response rate after the first mailing, a pilot study with stamped return envelopes was conducted. Comparison of the return rates revealed only a slightly higher response rate with stamps. For methodological consistency, half of the remaining packets were mailed with stamps on the return envelope.

\section{Survey}

The one page, confidential survey was constructed using previous research as a guide $(9,10)$. The survey requested demographic data, information about the number 
and nature of assaults and threats received during residency, and the number of hours of violence management training received. In addition, information pertaining to perceived reasons for assault and threat, resident reactions to violence, and general training experiences were also solicited.

Analyses

Resident characteristics were assessed using the Statistical Package for the Social Sciences (SPSS for Windows). Descriptive statistics were used to tabulate demographic characteristics and rates of assault and threat. Correlational and logistic regression analyses were used to assess the relationship between demographic characteristics and assault and threat.

\section{RESULTS}

Completed surveys were received from 517 (20\%) of current residents. To correct for selection bias, demographic and outcome data were weighted by residency program size (Total $\mathrm{N} \times .5 / 100)$.

\section{Sample Characteristics}

The sample was $51.5 \%$ male, ranging in age from 25 to 61 years (average age $=$ 33.1 years). Average age of males (32.9 years, $\mathrm{SD}=6.28)$ and females (33.4 years, $\mathrm{SD}=6.6)$ was not significantly different from national data (11; average age male $=$ 35 years, female $=34$ years). There were no significant differences in the number of males and females in each training year. Average program size was 38 residents $(\mathrm{SD}=15.9)$, with $13.3 \%$ in first year of training, $30.9 \%$ second, $27.7 \%$ third, and $25.4 \%$ fourth.

Dividing the U.S. by time zones, $52.8 \%$ were received from the East, $25.5 \%$ Mideast, 5.2\% Midwest, and 16.4\% West. Lower percentages for the Midwest and West were explained in part by the fact that four states in Midwest were not randomly selected to be surveyed and that there are only four states in the West coast time zone. Fifty four percent (277) of the envelopes received had been pre-stamped revealing nearly equal response rates for the stamped and unstamped return envelope conditions.

\section{PREVALENCE AND INCIDENCE OF VIOLENT ACTS BY PATIENTS}

Assault

Table 2 summarizes the results of the survey for assault. Approximately $36 \%$ of residents reported a total of 630 assaults. Thirty four percent of females and $37 \%$ males had been assaulted. Fifteen percent were in the first year of residency, 34\% second, $22 \%$ third, and $28 \%$ fourth. The number of assaults reported did not differ 
TABLE 1.

National Statistics for Psychiatric Residents

\begin{tabular}{ccccc}
\hline Year & Total & $\begin{array}{c}\text { Female } \\
(n)\end{array}$ & $\begin{array}{c}\text { Male } \\
(n)\end{array}$ & Unknown \\
\hline PGY1 & $N$ & 521 & 572 & 79 \\
PGY2 & 1172 & 592 & 713 & 31 \\
PGY3 & 1336 & 564 & 756 & 26 \\
PGY4 & 1346 & 591 & 746 & 3 \\
\hline
\end{tabular}

Note. Data obtained from FREIDA (Fellowship and Residency Electronic Interactive Database System), 1996. PGY-postgraduate year.

significantly between males and females across training levels. While age and training level were significantly correlated $(\mathrm{r}=.35, p<.001)$, Spearman rho correlations and logistic multivariate analyses investigating the relationship between age, training level, hours of violence management training, height, weight and assault were not significant.

Approximately $1 \%$ of assaults involved serious physical harm requiring immediate medical attention (e.g., stabbing), 1\% involved moderate physical harm requiring medical treatment (e.g., eye patch), 20\% involved mild physical harm not requiring medical attention, (e.g., scratch or bruise), $46 \%$ involved potential to harm (e.g., actions with aggressive intent in which no physical contact made), and 32\%

TABLE 2.

Resident Assault and Threat Characteristics

\begin{tabular}{ccc}
\hline Item & Assault & Threat \\
\hline Percent & $35.9 \%(54)$ & $73.9 \%(112)$ \\
$N$ of Acts & 630 & 1,853 \\
Age Group & $38.8 \%(19)$ & $73.6 \%(37)$ \\
$<30$ years & $38.7 \%(21)$ & $75.5 \%(42)$ \\
$30-34.9$ & $34.9 \%(07)$ & $76.2 \%(15)$ \\
$35-35.9$ & $24.6 \%(03)$ & $64.4 \%(08)$ \\
$40-44.9$ & $24.3 \%(02)$ & $77.3 \%(05)$ \\
$45-49.9$ & $28.8 \%(01)$ & $71.2 \%(01)$ \\
$50-54.9$ & $0.0 \%(00)$ & $100 \%(01)$ \\
$55-59.9$ & $0.0 \%(00)$ & $100 \%(01)$ \\
60-65 & $37 \%(29)$ & $79 \%(62)$ \\
Gender & $34 \%(25)$ & $69 \%(50)$ \\
Male & & \\
Female & $15 \%(08)$ & $13 \%(14)$ \\
Training Year & $34 \%(18)$ & $31 \%(34)$ \\
PGY 1 & $22 \%(12)$ & $28 \%(31)$ \\
PGY 2 & $28 \%(15)$ & $27 \%(30)$ \\
PGY 3 & &
\end{tabular}

Note. Weighted sample size data in parentheses. 
TABLE 3.

\section{Severity and Types of Violence}

$\begin{array}{lr}\text { Severity } & \\ \text { Serious Injury } & 2 \%(03) \\ \text { Moderate Injury } & 1 \%(02) \\ \text { Mild Injury } & 20 \%(35) \\ \text { Potential to Harm } & 46 \%(81) \\ \text { Aggressive Intent } & 32 \%(58) \\ \text { Types of Violence } & \\ \text { Throwing } & 20 \%(29) \\ \text { Spitting } & 13.7 \%(21) \\ \text { Pushing } & 12.8 \%(19) \\ \text { Grabbing } & 12.1 \%(18) \\ \text { Punching } & 7.4 \%(11) \\ \text { Slapping } & 4.6 \%(07) \\ \text { Kicking } & 4.1 \%(06) \\ \text { Wrestled to ground } & 1.1 \%(02) \\ \text { Pinned to wall } & .9 \%(01) \\ \text { Pinned to floor } & .5 \%(01)\end{array}$

Note. Weighted sample size data in parentheses.

involved aggressive intent (e.g., shove). Additionally, 26\% of residents had been attacked more than once.

Types of violence included throwing (20\%), spitting (13.7\%), pushing (12.8\%), grabbing $(12.1 \%)$, punching $(7.4 \%)$, slapping (4.6\%), and kicking $(4.1 \%)$. Only $1.1 \%$ had been wrestled to ground, $.9 \%$ pinned to the wall, and $.5 \%$ pinned to the floor.

\section{Threat}

Seventy four percent of residents reported a total of 1,853 threats. A larger proportion of males (79\%) had been threatened (females $=69 \%$ ), and this was consistent across training years. Of residents reporting threats, $13 \%$ were in the first year of residency, $31 \%$ second, $28 \%$ third, and $27 \%$ fourth. Seventy six percent of threats were described as verbal threats made face-to-face, $12 \%$ had been reported to a third person, $9 \%$ were verbal threats made over the phone, and $2.7 \%$ were written. Finally, age, training level, number of hours of violence management training, height, weight, were also not significantly related to threat rates.

TABLE 4.

Threat Types

\begin{tabular}{lcc}
\hline \multicolumn{1}{c}{ Type } & Percent & Weighted $N$ \\
\hline Verbal face to face & $76 \%$ & 425 \\
Third person & $12 \%$ & 66 \\
Verbal by phone & $9 \%$ & 51 \\
Written & $2.7 \%$ & 15 \\
\hline
\end{tabular}




\section{DISCUSSION}

Despite our low response rate, we were able to recruit the largest sample of psychiatric residents to date. Of the 517 residents responding, 36\% had been assaulted at least once during their training. This estimate is lower than all previous studies, but it is still an alarmingly high rate suggesting a high potential for injury due to patient violence at the residency level. Fortunately, very few assaults involved serious harm, with most involving mild physical harm or actions suggesting potential to harm (throwing, pushing, spitting, and grabbing). Furthermore, the majority of assaulted residents had only one violent encounter. Nonetheless, residents are clearly not immune to severe attacks and carry a small yet significant risk of actual physical injury due to patient attack.

A potential gender effect was not confirmed, with males and females having similar assault rates. This finding confirms those of Fink et. al (1991) suggesting equal risk of patient violence for male and female residents. It is possible that previous significant findings reflected spurious effects due to methodological problems (e.g., small sample sizes). However, it is possible given the limited response rate of the present study that the current findings may underestimate the number of females assaulted, particularly if a significant number of assaulted female residents chose not to return this survey.

While a resident may never experience an assault during their training, the chances for being threatened are quite high. Three out of four residents in our survey had been threatened during their training suggesting that verbal attacks are very common. Given the nature of the work, this finding is far from surprising. However, since most threats were made face-to-face, residents would be wise to be prepared to handle heated words from patients. A cold, unsympathetic, upset, or anxious resident is likely to be perceived very differently compared to a calm and reassuring resident. Observation of other professionals may help residents develop skills for responding to verbal threats. Also helpful may be role playing with colleagues which may facilitate the development of an appropriate verbal and behavioral style for interaction with violent patients.

Height and weight were not found to be related to assault and threat. While it is not surprising that residents' physical size was not related to the incidence of physical and verbal violence, the lack of relationship between number of violence management training hours and number of assaults and threats was unexpected. This suggests that the number of allotted program hours in violence management training did not relate to the occurrence of assault or threat. However, it is possible that informal/on the job training may be related to resident's chances of experiencing patient violence. Additionally, treatment setting (i.e., high risk versus low risk facility) and patient characteristics (e.g., psychotic versus neurotic) are also likely to influence residents' chances of attack or threat (5).

Finally, fewer surveys were completed by first year residents, which was not unexpected in light of national statistics showing declines in 1996 enrollments (Table 1). It is possible that fewer first year residents were sampled. Alternatively, 
fewer first years may have responded to the survey, potentially viewing it as irrelevant at their point in training.

Before concluding, a note of caution is raised in the interpretation of these findings given that rates of assault and threat may have been affected by several sources of potential bias (survey distribution by resident directors, sampling, memory for assault/threat, response rate). The need for study replication is underscored. However, the strengths of this study included its broad geographic scope, large sample size, and detailed documentation of the types of violence experienced by psychiatric residents.

While the focus was on resident characteristics, equally important to consider in future investigations are patient, institutional, and situational variables. Future research would do well to consider both sides of the violence issue. For example, examining personality variables of both patients and professionals concomitantly may help to explicate the nature, origins, and consequences of patient violence. As additional research findings are integrated into current research, priority groups for potential intervention may be identified. Furthermore, once the size and burden of patient violence is better understood, program directors and policy boards may be better able to estimate funding and training requirements, as well as identify priority groups for potential intervention. These are very important issues related to the safety of current and future professionals in the field of psychiatry.

\section{REFERENCES}

1. Gray GE: Assaults by patients against psychiatric residents at a public psychiatric hospital. Acad Psychiatry 1989; 13: 81-85.

2. Ruben I, Wolkon G, Yamamoto J: Physical attacks on psychiatric residents by patients. J Nerv Ment Dis 1980; 168: 243-245.

3. Chaimowitz GA, Moscovitch A: Patient assaults against psychiatric residents: the Canadian experience. Can J Psychiatry 1991; 36: 107-111.

4. Fink D, Shoyer B, Dubin WR: Study of assaults against psychiatric residents. Acad Psychiatry 1991; 15: 94-99.

5. Black KJ, Compton WM, Wetzel M, et al: Assaults by patients on psychiatric residents at three training sites. Hosp Community Psychiatry 1994; 45: 706-710.

6. Milstein V: Patient assaults on residents. Indiana Med 1987; 80: 753-755.

7. Carmel H, Hunter M: Psychiatrists injured by patient attack. Bull Am Acad Psychiatry Law 1991; 19: 309-316.

8. Madden DJ, Lion JR, Penna MW: Assaults on psychiatrists by patients. Am J Psychiatry 1976; 133: 422-425.

9. Fink, D. Violence and psychiatric residency, in Patient Violence and the Clinician. Edited by Eichelman BS, Hartwig AC. American Psychiatric Press, 1995: 33-41.

10. Faulkner LR, Grimm NR, McFarland BH, et al: Threats and assaults against psychiatrists. Bull Am Acad Psychiatry Law 1990; 18: 37-46.

11. FREIDA (Fellowship and Residency Electronic Interactive Database System). American Medical Association, 1996. 